\title{
Exposiciones Universales: nuevas contribuciones y agendas de investigación*
}

\author{
Universal Exhibitions: new contributions and \\ research agendas
}

Paula Bruno**

Notas críticas sobre los siguientes libros: Uslenghi, Alejandra, Latin America at Fin-de-Siecle Universal Exhibitions: Modern Cultures of Visuality, New York, Palgrave Mcmillan, 2016; Boone, M. Elisabeth, "The Spanish Element in Our Nationality": Spain and America at the World's Fairs and Centennial Celebrations, 1876 to 1915, Pennsylvania, Pennsylvania State University Press, 2019; Nelleke Teughels \& Peter Scholliers, P. (eds.), A Taste of Progress: Food at International and World Exhibitions in the Nineteenth and Twentieth Centuries, London/New York, Routledge, 2016; Boussahba-Bravard, Myriam \& Rebecca Rogers (eds.), Women in International and Universal Exhibitions, 1876-1937, London/New York, Routledge, 2017.

Las exposiciones universales fueron escenarios concretos en los que se pretendía representar el mundo conocido en una escala visitable, como su denominación indica. Hace décadas que la historiografía de distintas latitudes se ocupa de ellas con distintas perspectivas y desde varias disciplinas y áreas del saber. Como objeto de estudio han llamado la atención de arquitectos, historiadores del arte y la cultura, historiadores de la economía y de la clase obrera ${ }^{1}$.

\footnotetext{
* $\quad$ Este texto se publicó en inglés en Tapuya: Latin American Science, Technology and Society, vol. 3, núm. 1. https://doi.org/10.1080/25729861.2020.1780722

** Argentina. Dra. en Historia por la Universidad de Buenos Aires. CONICET (Consejo Nacional de Investigaciones Científicas y Técnicas), Argentina.pbruno@conicet.gov.ar 1 La bibliografía sobre Exposiciones Universales es copiosa. Puede consultarse la exhaustiva bibliografía ordenada que han realizado Alexander Geppert, Jean Coffey y
} 
Aunque algunas exposiciones comenzaron a realizarse a lo largo del siglo XIX y estuvieron asociadas a un tarea productiva o creativa específica -por ejemplo: maquinarias o artes decorativas- fue en 1851, cuando se realizó una exposición en Londres, cuando el formato de las exposiciones se estandarizó. Desde entonces, las exposiciones devinieron maquetas del mundo conocido.

Las ciudades europeas y americanas que alojaron las sucesivas exposiciones se convirtieron en espacios en los que se desplegaban, en simultáneo, otros eventos asociados a ellas, o que pretendían captar al mismo público que convocaban. En algunas ocasiones, de hecho, estas exposiciones se superpusieron con celebraciones centenarias o con efemérides locales o nacionales.

La "edad de oro" de las exposiciones universales, como la consideran varios historiadores, coincidió con las décadas finales del siglo XIX y comienzos del siglo XX. Durante estos años tuvo lugar una clara reconfiguración de la geopolítica mundial, por un lado; por otro, se trató de un momento histórico caracterizado (aunque con algunas diferencias en lo que concierne a cronologías) por el afianzamiento de las naciones y la invención de las identidades nacionales. La era del imperialismo, la Guerra de 1898 entre España y Estados Unidos, las tensiones y competencias entre naciones de Europa, los efectos del expansionismo norteamericano, la Primera Guerra Mundial, la Revolución Mexicana y la Revolución Rusa, por mencionar solamente algunos hitos, fueron telón de fondo de las dinámicas de estas décadas

De este modo, rivalidades nacionales y competencia entre naciones se superponían dentro de los espacios que las exposiciones generaban. Los esfuerzos por representar a las naciones se expresaban claramente en los llamados pabellones nacionales. En cada uno de ellos, las naciones pretendían representarse por medio de una selección de productos naturales, manufacturas, piezas arqueológicas, artísticas y literarias, entre tantas otras. Cada pabellón nacional intentaba, en suma, ser una maqueta de una nación.

Tammy Lau disponible en línea en el siguiente enlace: https://www.geschkult.fu-berlin. de/e/fmi/astrofuturismus/publikationen/Geppert_-_Expo_bibliography_3ed.pdf Vigente el $01 / 10 / 2020$ 
Distintas historiografías específicas abordaron, entre las décadas de 1980 y 2000 temas ligados a las exposiciones universales. Desde una perspectiva de historia económica, por ejemplo, se han estudiado las exposiciones como espacios en los que se hacía explícita la competencia industrial capitalista entre naciones y cómo cada estado intentaba mostrar sus logros industriales y tecnológicos, y su superioridad en armamentos. En este sentido, las exposiciones han sido pensadas como un engranaje más de la sociedad capitalista industrial.

Otras perspectivas han estudiado a las exposiciones en la era del imperialismo para evaluar las formas en las que el dominio colonial fue escenificado. Especialistas en estudios culturales han mostrado cómo distintas ideas sobre civilización, progreso y atraso, o sobre formas del exotismo y el romanticismo operaron como articuladoras para mostrar formas de dominación legitimadas y naturalizadas en las exposiciones.

Por otros caminos, críticos culturales e historiadores del arte han estudiado las exposiciones como espacios de cultura visual. Recuérdese que en su seno se desplegaron todo tipo de espectáculos visuales, entre los que se destacan los dioramas, los panoramas, y las expresiones cinematográficas. Pero también se han estudiado las culturas visuales en un sentido más clásico del término; de este modo, se cuenta con estudios sobre colecciones nacionales y "universales" de arte. Desde los estudios urbanos y de la cultura material, a su vez, se han estudiado las ciudades que fueron epicentros de las exposiciones, los edificios que se construyeron para alojarlas, y los monumentos construidos para ser inaugurados en ocasión de las exposiciones, muchos de ellos considerados íconos de las ciudades, y también las arquitecturas efímeras. Entre estas perspectivas de estudio, las observaciones de Walter Benjamin sobre las exposiciones ha sido una referencia recurrente. Así, con distintos acentos, se ha utilizado en estos estudios reiteradas veces la noción de la exposición universal como un dispositivo de modernidad tal como se entendía en Occidente a fines del siglo XIX y comienzos del XX. Y se las ha pensado en relación a otras formas de exposición y vidrierismo, como los museos y bazares. Se ha pensado también en las funciones pedagógicas de las exposiciones en tanto que reforzaron ciertos sentidos de superioridad y dominación al ordenar y exponer el mundo en vidrieras y vitrinas. 
Varias de estas historiografías se desenvolvieron al calor de las grandes preguntas planteadas en las décadas comprendidas entre 1980 y 2000 sobre la conformación de naciones y de identidades nacionales. A lo largo de la década del 2000, en cambio, comenzaron a plantearse nuevas preguntas historiográficas que apuntaron a pensar más allá de las historiografías nacionales y a preguntarse por los contactos, las transferencias, y las interrelaciones entre regiones del mundo. De este modo, comenzaron a tener presencia vertientes de historia atlántica, historia cruzada, historia conectada y, ya más en torno a 2010, historia global o transnacional. En las nuevas líneas historiográficas que se desplegaron desde entonces, como ha señalado Anne Marie Thiesse se comenzaron a estudiar las exposiciones internacionales en tanto lugares privilegiados de exhibiciones identitarias, hecho que permite constatar, como esta historiadora francesa ha señalado, que no hay nada más internacional que la formación de las identidades nacionales ${ }^{1}$.

Propongo aquí pensar a la luz de estas nuevas líneas historiográficas los libros de reciente aparición seleccionados para este comentario. Si bien en ellos se recuperan varias de las agendas de las décadas anteriores, pueden verse algunos acentos o modulaciones que muestran la productividad de las nuevas preguntas que circulan en las mencionadas historiografías. De los cuatro libros leídos para pensar este comentario, dos son libros monográficos de autor (Uslenghi y Boone) y los otros dos volúmenes colectivos (compilados por Boussahba-Bravard y Rogers, y Teughels y Scholliers). Por lo tanto, dedico aquí algunos comentarios generales a ellos y sugiero enfáticamente la lectura de cada uno.

El libro de Uslenghi es, quizás, el que dialoga más fuertemente con las líneas destacadas para las décadas anteriores. Su intención es dar cuenta de las "narrativas visuales" tal como fueron retratadas por destacados y conocidos escritores (Rubén Darío, Enrique Gómez Carillo, Manuel Ugarte y Amado Nervo) en el cambio del siglo XIX al XX. Si la cultura visual liga al libro con contribuciones anteriores, la recurrente referencia a la forma de pensar las exposiciones que propuso hace décadas Walter Benjamim es otro punto en común con

1 Anne Marie Thiesse, La creación de las identidades nacionales. Europa: siglos XVIII-XX, Santiago de Compostela, Ézaro, 2010. 
estos aportes. El foco de la autora está puesto en pabellones nacionales y escritores de América Latina. A lo largo de sus páginas la originalidad radica más en pensar las "narrativas visuales" que en aportar nuevas voces al coro de escritores conocidos de la época que dejaron testimonios escritos de las exposiciones europeas, sobre todo las realizadas en París. Otra novedad interpretativa se puede ver en la intención de pensar a los escritores latinoamericanos en una clave cosmopolita -en tensión con imaginarios nacionales- como varios estudios de los últimos diez años han propuesto. Uslenghi recorre de manera creativa, por su parte, fuentes que en general son más pensadas como dadoras de información que como objetos en sí mismas, se destacan entre ellas: libros celebratorios, cartografías, postales, y piezas cinematográficas. Por medio de esta estrategia, la autora aporta a miradas de escritores conocidos nuevas dimensiones para pensar en qué tipo de espectador se podía convertir un escritor latinoamericano en el marco de una exposición universal y cómo podía para participar performativamente de esa experiencia.

El libro de Boone, por su parte, a la luz de la reconstrucción exhaustiva de las exposiciones de arte, las apuestas arquitectónicas, y otros elementos de cultura visual de numerosas exposiciones universales realizadas en las Américas y en Europa, tiene como objetivo pensar en los elementos de hispanidad que subyacen sordamente a las identidades americanas del Norte y del Sur. La autora se nutre de las nuevas preguntas respecto de las identidades múltiples o superpuestas como posibilidades para complejizar la historia de las narrativas identitarias nacionales. Se destaca en el libro la apuesta por pensar en figuras con apropiaciones complejas, como la de Cristóbal Colón, y la de poner en sintonía eventos americanos y europeos, atendiendo a celebraciones centenarias y exposiciones en el período comprendido entre 1876 y 1915. Este libro ofrece al lector interesado una excelente puerta de entrada para pensar las culturas visuales en diálogo con los objetivos de las naciones a la hora de conformar colecciones que sintetizaban los imaginarios nacionales $y$, a la vez, descubrir qué elementos se incluían y excluían en la conformación de esos cánones. Desde mi perspectiva es, a su vez, un aporte para pensar la construcción de patrimonios nacionales de manera más dinámicas y atenta a elementos y actores de muy diferente tenor. 
Las dos compilaciones aquí comentadas, por su parte, presentan agendas que, tomando a las exposiciones universales como escenarios -más que como objetos de estudio- realizan recortes sobre actores y temas poco transitados en las historiografías de las décadas anteriores. El libro curado por Rogers y Boussahba-Bravard, recorre, para el período 1876-1937, distintos episodios y procesos que tienen a mujeres por protagonistas. A lo largo de las partes y capítulos del libro se leen contribuciones que, desde la historia cultural o desde la perspectiva biográfica, ponen en el centro de la escena a coleccionistas, artistas plásticas, estudiantes, profesionales y trabajadoras, mujeres en los márgenes (por su origen étnico o su pertenencia geográfica) que, en el marco de las exposiciones universales, pusieron en práctica para hacer escuchar sus intervenciones en tanto portavoces de temas que van desde la defensa de la identidad nacional hasta el feminismo con dimensiones transnacionales. La intención del libro de poner de relieve a las mujeres como protagonistas en estos escenarios permite pensar a estas exposiciones como espacios dinámicos de construcción de identidades no siempre en sintonía. Por ejemplo, muestra cómo algunas voceras que se hacían escuchar en estos eventos estaban convencidas de la necesidad de encarnar un imaginario nacional, pero, a la vez, de darle una dimensión regional o transnacional a las formas de feminismo que se desplegaron en estas décadas. Desde mi perspectiva, y quizás sin proponerlo de manera explícita, el libro opera también como una invitación para repensar el rol de algunas mujeres en las intersecciones entre espacios público y privados; sobre todo porque muestra los borramientos de fronteras entre ambos que propiciaba la alteración radical de los tiempos y los espacios de las ciudades que oficiaban como anfitrionas de las exposiciones universales.

El volumen compilado por Teughels y Scholliers, por su parte, se inscribe en el prolífico campo de la historia de la comida, que en los últimos años ha desplegado líneas de amplia productividad historiográfica. El libro hace un llamamiento a pensar en la conformación de otro tipo de cánones nacionales, distintos a los literario o a los artísticos, pero con un nivel de impacto más amplio en las sociedades. Las preguntas acerca de las gastronomías autóctonas o locales, la idea misma de productos de "esta" tierra, y la construcción de mitos respecto de cómo un producto o una receta representa a una ciudad, a una 
nación, o una etnia son las que atraviesan los textos que conforman el volumen. El libro funciona también como una invitación para pensar en los sentidos comunes que se generan en torno a imágenes fuertes relacionadas con identidades y consumos gastronómicos -solamente para mencionar una de impacto masivo: ipiénsese en la relación automática que incluso hoy se hace entre parisinos y baguettes!-. A su vez, como lectora, me ha sugerido varias pistas interesantes para repensar a las exposiciones universales como espacios de ritualidad nacional en la que podían surgir nuevas ritualidades asociadas a la comida y sus apropiaciones. El volumen puede ser recorrido tanto por interesados en la historia de las naciones y de la invención de las mismas, como por curiosos interesados en la gastronomía y sus dinámicas de producción y circulación. 
